Review

\title{
Computer simulation applied to the biological control of the insect Aphis gossypii for the parasitoid Lysiphlebus testaceipes
}

\author{
A.A. de Souza ${ }^{a}$, S.G.F. Martins ${ }^{\mathrm{a}, *}$, M.S. Zacarias ${ }^{\mathrm{b}}$ \\ a Departamento de Ciências Exatas, Universidade Federal de Lavras, Caixa Postal 3037, CEP: 37200-000, Lavras-MG, Brazil \\ ${ }^{\mathrm{b}}$ Embrapa Caf/Ecocentro, Campus UFLA, Caixa Postal 176, CEP: 37200-000, Lavras-MG, Brazil
}

\section{A R T I C L E I N F O}

\section{Article history:}

Received 20 June 2008

Received in revised form

20 November 2008

Accepted 2 December 2008

Available online 29 January 2009

\section{Keywords:}

Aphis gossypii

Parasite

Biological control

Penna model

\begin{abstract}
A B S T R A C T
In integrated pest management (IPM), biological control is one of the possible options for the prevention or remediation of an unacceptable pest activity or damage. The success of forecast models in IPM depends, among other factors, on the knowledge of temperature effect over pests and its natural enemies. In this work, we simulated the effects of parasitism of Lysiphlebus testaceipes (Cresson, 1880) (Hymenoptera: Aphidiidae) on Aphis gossypii (Glover, 1877) (Hemiptera: Aphididae), a pest that is associated to crops of great economic importance in several parts of the world. We made use of experimental data relative to the host and its parasitoid at different temperatures. Age structure was incorporated into the dynamics through the Penna model. The results obtained showed that simulation, as a forecast model, can be a useful tool for biological control programs.
\end{abstract}

(c) 2008 Elsevier B.V. All rights reserved.

\section{Contents}

1. Introduction

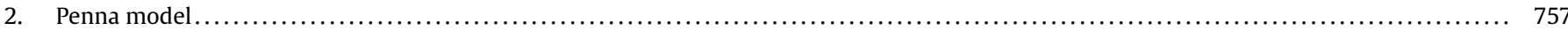

3. Experimental comments about $A$. gossypii and its parasitoid $L$. testaceipes ...................................................... 757

4. Computer simulation of the dynamics of interaction of the apterous morphs of A. gossypii and its parasitoid L. testaceipes .................. 758

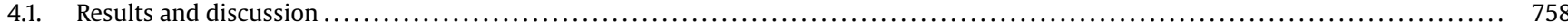

5. Computer simulation of the dynamics of interaction of the apterous and alate morphs of A. gossypii and its parasitoid L. testaceipes ........... 759

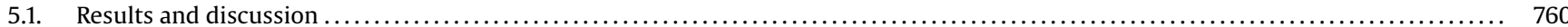

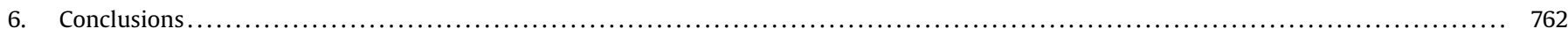

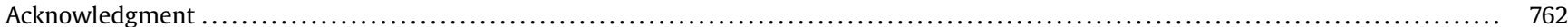

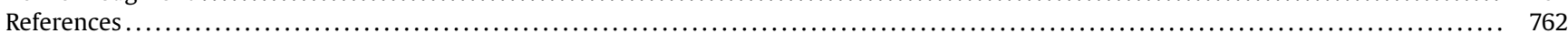

\section{Introduction}

Aphids are insect-pests that cause the largest damages in protected crops and cultures in the field. These insects are responsible for the transmission of a great number of virus diseases to plants, resulting in considerable losses to their commercialization.

In integrated pest management (IPM) (Zambolim, 2000), biological control is one of the possible options for the prevention or remediation of an unacceptable pest activity or damage. The use of

\footnotetext{
* Corresponding author. Tel.: +55 35 38291383; fax: +55 3538291372 .

E-mail addresses: solangemarti@gmail.com (S.G.F. Martins), zacarias@epamig.ufla.br (M.S. Zacarias).
}

natural enemies to control agricultural pests, avoiding the use of toxic substances, is one of the most efficient options adopted worldwide. In biological control programs of aphids, parasitoids are the most efficient natural enemies (Bueno, 2005).

The insect Aphis gossypii Glover, 1877 (Hemiptera: Aphididae) is a pest of agricultural importance in several parts of the world, including Brazil. Among the main factors that make its control difficult are a great number of host species, tolerance to extreme temperatures, and high fecundity (Sampaio et al., 2005). The introduction of parasitoids, or more rare predators, has been successful in the task of biological control of pests. The parasitoid, Lysiphlebus testaceipes (Cresson, 1880) (Hymenoptera: Aphidiidae), that has A. gossypii as one of its hosts, is a dominant parasitoid species in South America. It also has a great potential as a biological control agent for aphids (Rodrigues et al., 2004). 
The knowledge of the effect of the physical factors on pests has great importance for designing integrated management strategies. Temperature is a natural factor of significant influence to the developmental time and behavior of insects. Rodrigues et al. (2004) measured the developmental time and parasitism of $L$. testaceipes on A. gossypii in different temperatures. The combination of a low developmental time, parasitism and emergence higher than $60 \%$ occurred at $25^{\circ} \mathrm{C}$ indicating that this temperature could be the most adequate for the reproduction and establishment of $L$. testaceipes as a biological control agent of $A$. gossypii in green houses.

An interesting aspect in the aphid life cycle is the presence of several asexual generations alternating with a single sexual generation. During the phase of asexual reproduction, aphids produce a number of different phenotypes, among which are winged (alate) and unwinged (apterous) morphs. The winged dispersal morph is mainly responsible for the colonization of new plants and, in many species, is produced in response to adverse environmental conditions. Weisser et al. (1999) verified that the presence of a predator enhanced the proportion of winged morphs among the offspring produced by the aphid Acyrthosiphon pisum (Harris). Pereira and Lomônaco (2003) verified that alate morphs of Brevicoryne brassicae (L.) were produced in the presence or absence of the parasitoid Diaeretiella rapae (McIntosh). However, in the presence of parasitoids, their number was significantly higher and they were produced earlier. The increased production of alate morphs in response to the presence of the parasitoid or predator can be considered a defense mechanism, because aphids could strategically continue to survive, escaping by flight.

Models for the dynamics of the pests (Sá Martins and Racco, 2001; Giarola et al., 2006; Oliveira et al., 2008) and its interaction with natural enemies (Mills and Getz, 1996; Freire et al., 2005; Bommarco et al., 2007; Stauffer et al., 2007) have attracted interest recently. Motivated by the cyclic pattern of reproductive regimes of the aphids, Sá Martins and Racco (2001) simulated the evolution of a population enduring harsh seasonal conditions for survival. Recently, Giarola et al. (2006) have simulated the population dynamics of $A$. gossypii insects in the absence of natural enemies using the Penna ageing model (Penna, 1995). Due to easy and efficient implementation on computers, the Penna model is extremely appropriated to numerical simulations.

In this work, using as reference experimental data related to parasitism of $L$. testaceipes on $A$. gossypii at different temperatures, we simulated the effects of parasitism on the population dynamics of apterous and alate morphs of $A$. gossypii. Considering the need for an age structure for the studies and that the reproductive mode of aphids in tropical regions is predominantly asexual, we used this version of the Penna model (Penna, 1995). This paper is organized as follows: in Section 2, we describe the asexual version of the Penna model; in Section 3 we present some relative experimental comments to A. gossypii and L. testaceipes; in Sections 4 and 5, we describe the model and present our results and discussions; and in Section 6, conclusions are presented.

\section{Penna model}

The Penna model (Penna, 1995) is a population dynamics model based on the evolutionary theory of mutation accumulation of aging. Mostly because of its features of easy and efficient implementation in computers, while allowing simple modifications in order to simulate very special characteristics or interactions. The Penna model has been successfully applied to many different situations on population dynamics, such as the catastrophic senescence of the Pacific salmon (Penna et al., 1995), vanishing of codfish due to overfishing (Oliveira et al., 1995), lobster fishing regulation (Penna et al., 2001), age-dependent host-parasite relations (Stauffer et al., 2007), besides the Gompertz exponential law for the mortality.
Table 1

Life expectancy and reproductive period, in days, and daily fecundity of apterous females of $A$. gossypii (average \pm half-length of the $95 \%$ confidence interval) at temperature of $15,20,25$, and $30^{\circ} \mathrm{C}$ (Soglia et al., 2003).

\begin{tabular}{lllll}
\hline & \multicolumn{4}{l}{ Temperature $\left({ }^{\circ} \mathrm{C}\right)$} \\
\cline { 2 - 5 } & 15 & 20 & 25 & 30 \\
\hline Life expectancy & $27.9 \pm 4.31$ & $21.8 \pm 2.03$ & $18.0 \pm 1.47$ & $12.5 \pm 2.11$ \\
Reproductive period & $17.5 \pm 1.8$ & $15.2 \pm 2.42$ & $14.3 \pm 1.20$ & $3.8 \pm 0.79$ \\
Daily fecundity & $1.8 \pm 0.10$ & $2.6 \pm 0.28$ & $3.1 \pm 0.22$ & $1.7 \pm 0.18$ \\
\hline
\end{tabular}

In the asexual Penna model, the genotype of each individual is represented by a sequence of bits (a string containing 0 's and 1 's), with a given length $B$, which should be interpreted as a transcription of its genetic code. Each bit corresponds to a given time interval in the individual's life history; typically, one bit corresponds to a few years if we are considering human population (most simulations have been done with $B=32$ bits), 1 day when referring to Drosophila and so on. Therefore, an individual will have a bit set to ' 1 ' in its bit-string at a position corresponding to the time when a mutation affects its survival. In the years that the individual does not suffer any effect of deleterious mutation, the bits in its string will be set to ' 0 '. The individual stay alive if the number of deleterious mutations which became active up to its current age is lower than a threshold $T$ (a parameter of this model).

If the individual reaches the age $R$ (minimum age at reproduction), then it can breed, generating $b$ offspring at each further age (including age $R$ ). The offspring inherits a copy of the parent's bit-string with the exception of $M$ randomly selected bits. These different $M$ bits represent point mutations at birth. In this work, we considered only deleterious mutations at birth, since they are more frequent than the good ones. Therefore, in the $M$ selected ages, the offspring bit-string will contain 1's. As usual in population dynamic studies, limitations of food and space are introduced into the model through a Verhulst factor (logistic). The individual will survive and will age by 1 year with probability $1-\left(N(t) / N_{\max }\right)$, where $N(t)$ is the population size at time $t$ and $N_{\max }$ is the carrying capacity of the environment. These simple rules define the dynamics of this model.

\section{Experimental comments about $A$. gossypii and its parasitoid $L$. testaceipes}

Temperature is among the abiotic factors that directly affect the behavior of insects. In laboratory conditions, Soglia et al. (2002, 2003) evaluated at different temperatures in chrysanthemum cultivars, the developmental time (duration from egg phase to adult phase), reproductive period, daily fecundity and life expectancy of apterous females of $A$. gossypii. It was verified that the temperature of $25^{\circ} \mathrm{C}$ is the more favorable for population growth of $A$. gossypii. For the cultivar Yellow Snowdon, the results are listed in Tables 1 and 2 . The intrinsic growth rate at $25^{\circ} \mathrm{C}$ was evaluated by Soglia et al. (2005) (Table 2).

The adaptability to climatic conditions is a key point for the success of mass-rearing and establishment of parasitoids in biological control programs. In this direction, Rodrigues et al.(2004) evaluated

Table 2

Average developmental time, in days, and intrinsic growth rate of apterous females of A. gossypii (Soglia et al., 2002, 2005).

\begin{tabular}{lllll}
\hline & \multicolumn{4}{l}{ Temperature $\left({ }^{\circ} \mathrm{C}\right)$} \\
\cline { 2 - 5 } & 15 & 20 & 25 & 30 \\
\hline Developmental time & 13 & 7 & 6 & 5 \\
Intrinsic growth rate $\left(r_{m}\right)$ & - & - & 0.31 & - \\
\hline
\end{tabular}


Table 3

Developmental time, in days, parasitism rate and emergency rate of $L$. testaceipes on A. gossypii (Rodrigues et al., 2004).

\begin{tabular}{lccll}
\hline & \multicolumn{4}{l}{ Temperature $\left({ }^{\circ} \mathrm{C}\right)$} \\
\cline { 2 - 5 } & 15 & 20 & 25 & 30 \\
\hline Developmental time & 16 & 10 & 8 & 8 \\
Parasitism rate & 0.76 & 0.68 & 0.65 & 0.40 \\
Emergency rate & 0.80 & 0.61 & 0.62 & 0.14 \\
\hline
\end{tabular}

the parasitism of $L$. testaceipes on A. gossypii maintained on chrysanthemum cultivar Yellow Snowdon at different temperatures. The results, as developmental time, ${ }^{1}$ parasitism rate, and emergence rate $^{2}$ are given in Table 3. The combination of a low developmental time and parasitism and emergency higher than 60\% occurred at $25^{\circ} \mathrm{C}$, indicating that this temperature could be the most adequate for the reproduction and establishment of $L$. testaceipes as a biological control agent of $A$. gossypii in protected cultivation.

\section{Computer simulation of the dynamics of interaction of the apterous morphs of $A$. gossypii and its parasitoid $L$. testaceipes}

In this work, we simulated the parasitism of $L$. testaceipes on colonies of A. gossypii maintained on chrysanthemum cultivar Yellow Snowdon at different constant temperatures, and then we compared the results with the experimental data. Since the parasitoid $L$. testaceipes is generalist, that is, a parasite also on other hosts, we assumed, for simplicity, that the population of parasitoids is not regulated by the population of $A$. gossypii. The parasitism was incorporated into the dynamics through probabilities given for experimental parasitism rates and developmental time of $L$. testaceipes (necessary period for mummification of the aphid) (Table 3). The effects of the different emergency rates were slighted. In this model the experimental parasitism rates reflect the combined effect of different factors that characterize the action of the parasitoid. The developmental time is one delay term because the aphids are eliminated of population after developmental time of $L$. testaceipes. We examined the effects of parasitism on the population of host temporarily exposed to the action of the parasitoid. Parasitism started in $t=61000$ (after a stable population is reached) and ended in $t=72000$. We can imagine that with $t=72000$ applied, for example, an insecticide has decimated the population of parasitoids.

Considering that the reproductive mode of aphids in tropical regions is predominantly asexual, we used the Penna model as presented previously in this work. The population of $N$ females whose genotypes are represented by four words of 32 bits, is identified by one Penna bit with 1 day. In such cases, the maximum age allowed for a female of population is 127 days. In addition to minimal age $(R)$, that is, developmental time, another factor is considered: a maximum age for reproduction $(R X)$, in other words, when a female reaches the age $R$ it can breed, generating $b$ offspring at each further age, until age $R X$. For each temperature $\left(15,20,25\right.$ and $\left.30^{\circ} \mathrm{C}\right)$, parameters such as minimum $(R)$ and maximum $(R X)$ age of reproduction and daily fecundity $(b)$ assumed values from experimental data in Tables 1 and 2.

Furthermore each female was to be parasitized only once, with probability given by parasitism rate $(\alpha)$. A parasitized female will certainly die after the developmental time $(\gamma)$ of $L$. testaceipes, until

\footnotetext{
${ }^{1}$ For the parasitoid, developmental time is the period from oviposition until mummification of the aphid (that is, the death's aphid.)

2 Emergence rate is the proportion of adult parasitoids that emerge after mummification of the aphid.
}

Table 4

Minimum age $(R)$, maximum age $(R X)$, both in days, and daily fecundity $(b)$ of $A$. gossypii. Developmental time $(\gamma)$ in days, and parasitism rate $(\alpha)$ of $L$. testaceipes on A. gossypii.

\begin{tabular}{lcccc}
\hline & \multicolumn{4}{l}{ Temperature $\left({ }^{\circ} \mathrm{C}\right)$} \\
\cline { 2 - 5 } & 15 & 20 & 25 & 30 \\
\hline$R$ & 13 & 7 & 6 & 5 \\
$R X$ & 30 & 21 & 19 & 8 \\
$b$ & 2 & 3 & 3 & 2 \\
$\gamma$ & 16 & 10 & 8 & 8 \\
$\alpha$ & 0.76 & 0.68 & 0.65 & 0.40 \\
\hline
\end{tabular}

then, it remains alive. This period, counted from the moment when the female was parasitized, is the necessary number of days for mummification of the aphid. $\alpha$ and $\gamma$ assumed values from experimental data in Table 3.

The model parameters which are dependent of temperature are shown in Table 4 . The other parameters, which are independent of temperature, were given the following values:

- carrying capacity: $N_{\max }=100000$

- number of mutations: $M=1$

- limit of deleterious mutations: $T=1$

With these parameters, the population dynamics follows the simple rules of the Penna model. Simulations were made up to 150000 time steps ("days"), considering an initial population of $N_{0}=10000$ females

\subsection{Results and discussion}

Fig. 1 shows the survival curves for parasitized and nonparasitized colonies of aphids obtained at different temperatures. The survival rates were obtained discarding the 100000 initial time steps. With temperatures of 15,20 and $25^{\circ} \mathrm{C}$, a reduction in the life expectancy and reproductive period of the insect due to the action of parasitoid was observed (He et al., 2005), despite removal of parasitism in $t=72000$. This indicates that parasitism affects the distribution of genotypes of the host population.

Parasitism has been suggested as the major selection factor that affects genetic diversity in populations (Duncan and Little, 2007; Gardner et al., 2007). Fig. 2 shows the frequency of genotypes $(f)$ with defective genes at age $j$ (if a bit is set for 1 , it is a defective gene). In Fig. 2(a)-(c), parasitism is observed to generates a selective pressure, except at $30^{\circ} \mathrm{C}(\mathrm{d})$, that modifies the distribution of genotypes even if the parasitoid is removed from the dynamics (it is not our purpose here to evaluate the issue of genetic diversity), changing the life expectancy of aphids. The reduction of the life expectancy and reproductive period of the aphids can be explained by parasitoids selecting the best genotypes. Best genotypes are those that confer to the individual the longest life expectancy and more descendants. With the temperature of $30^{\circ} \mathrm{C}$, it no longer has selective pressure due to low probability of parasitism $(\alpha)$ combined with a long developmental time $(\gamma)$ of the parasitoid (Table 3 ) in comparison to the life expectancy of the host.

The growth rate of the population $(\lambda(t))$, that represents the factor of growth of the population for a generation or another period, was calculated in accordance with the discrete logistic equation (Bernardes et al., 1998):

$N(t+1)=\lambda(t) N(t) \frac{1-N(t)}{N_{\max }}$

Table 5 lists the average values at different temperatures for intrinsic growth rate $r_{m}(t)$, defined as $r_{m}(t)=\ln (\lambda(t)$ ) (Neto et al., 1976), for parasitized and non-parasitized colonies of aphids. 

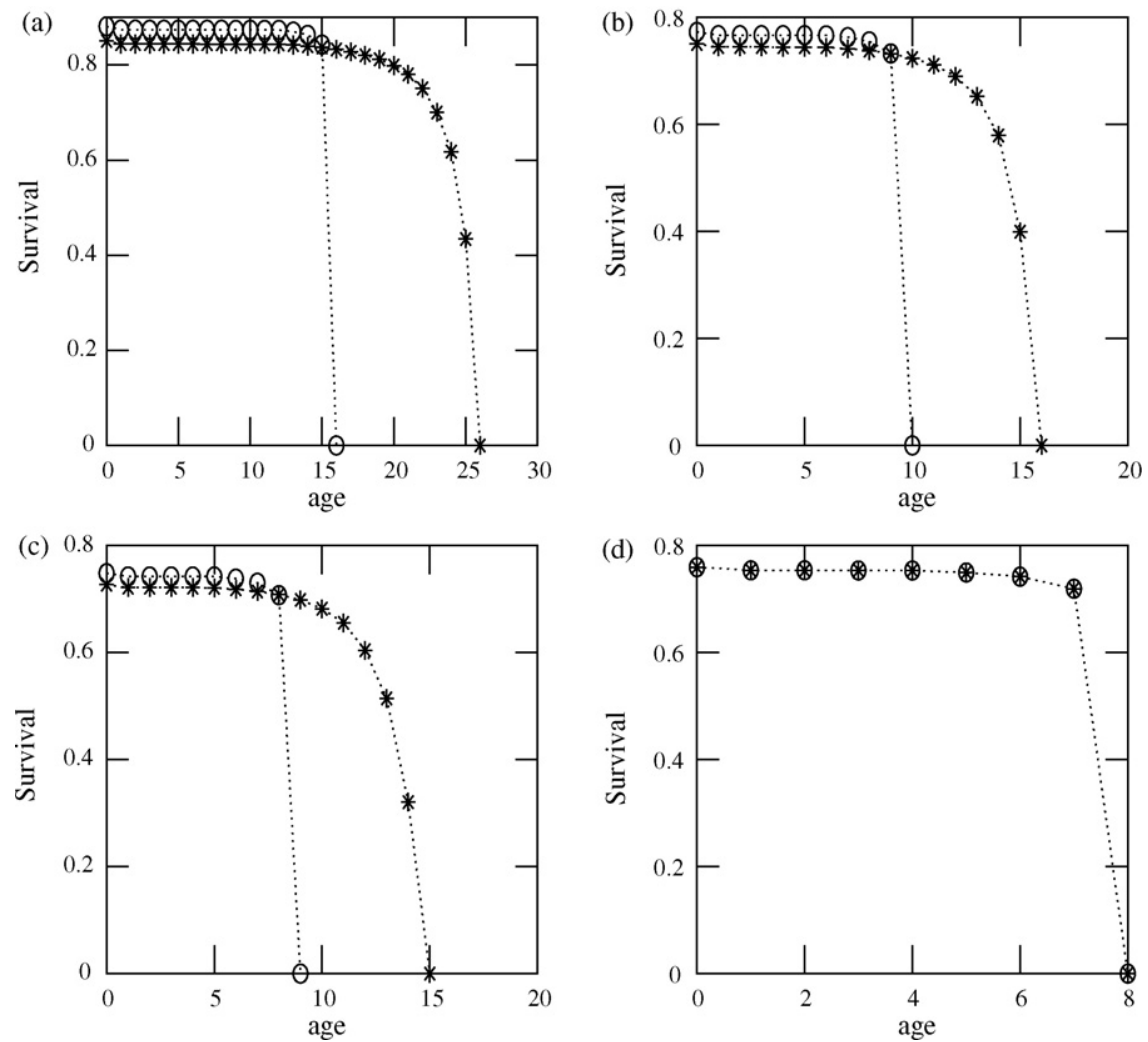

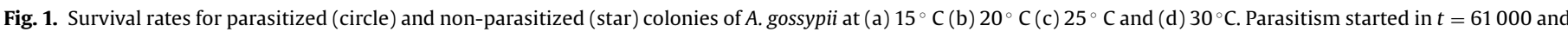
ended in $t=72000$. Simulations up to 150000 time steps.

During parasitism, a higher reduction in intrinsic growth rate is observed at $25^{\circ} \mathrm{C}$, that is, greater efficiency of the parasitoid $L$. testaceipes, although in this temperature, the highest probability of parasitism does not occur. This is in accordance with the results of Rodrigues et al. (2004) when affirming that among the studied temperatures, $25^{\circ} \mathrm{C}$ is ideal for the development of the L. testaceipes. In the absence of parasitism, the average value for intrinsic growth rate at $25^{\circ} \mathrm{C}$ is according to the experimental result obtained by Soglia et al. (2005) (Table 2). After the parasitoid was removed ( $t>72000$ ), an increase in temperature diminishes differences between the average values for intrinsic growth rate of the population in the absence and after the removal of the parasitism (a higher reduction is observed at $15^{\circ} \mathrm{C}$ ). This occurs because the probability of parasitism diminishes when temperature increases and, therefore, it increases the probability of the best genotypes to escape the action of parasitoids.

Fig. 3 shows the temporal evolution of the size of the population $(N(t))$ at different temperatures for parasitized and non-parasitized colonies of A. gossypii. In the presence of parasitism, a higher reduction in the size of the population at temperature of $25^{\circ} \mathrm{C}$ (reduction of $72 \%$ ) is observed. As parasitism affects the intrinsic growth rate of the population, differences between the average values of the population are observed before $(t<61000)$ and after the removal of parasitism $(t>72000)$ at 15,20 , and $25^{\circ} \mathrm{C}$.

\section{Computer simulation of the dynamics of interaction of the apterous and alate morphs of $A$. gossypii and its parasitoid $L$. testaceipes}

The production of alate morphs in response to the presence of the parasitoid or predator can be considered a defense mechanism. The purpose of this simulation is to verify as this defense mechanism affect the selective pressure generate by parasitism. The temperature $25^{\circ} \mathrm{C}$, the most adequate for reproduction and establishment of $L$. testaceipes as a biological control agent of $A$. gossypii in protected cultivation, was considered. It was assumed that only the apterous morphs are parasitized because the alates are able to escape by flight. As in previous simulation, parasitism started in $t=61000$ (after a stable population is reached) and ended in $t=72000$. Parameters such as minimum $(R)$ and maximum $(R X)$ age of reproduction, daily fecundity $(b)$, developmental time $(\gamma)$ and parasitism rate $(\alpha)$ assumed values at $25^{\circ} \mathrm{C}$ as given in Table 4 .

When the female reaches the minimum reproduction age $R$, it will be able to generate $b$ offspring with one given probabil-

Table 5

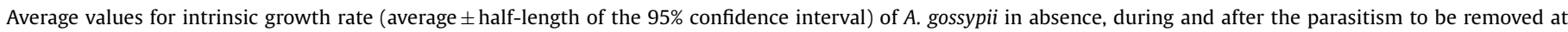
temperature of $15,20,25$, and $30^{\circ} \mathrm{C}$.

\begin{tabular}{|c|c|c|c|}
\hline \multirow[t]{2}{*}{ Temperature $\left({ }^{\circ} \mathrm{C}\right)$} & \multicolumn{3}{|c|}{ Average intrinsic growth rate } \\
\hline & Absence of parasitism & During the parasitism & After parasitism \\
\hline 15 & $0.161 \pm 0.004$ & $0.060 \pm 0.008$ & $0.126 \pm 0.007$ \\
\hline 20 & $0.286 \pm 0.004$ & $0.166 \pm 0.008$ & $0.257 \pm 0.005$ \\
\hline 25 & $0.318 \pm 0.004$ & $0.052 \pm 0.012$ & $0.289 \pm 0.005$ \\
\hline 30 & $0.274 \pm 0.004$ & $0.206 \pm 0.005$ & $0.274 \pm 0.004$ \\
\hline
\end{tabular}



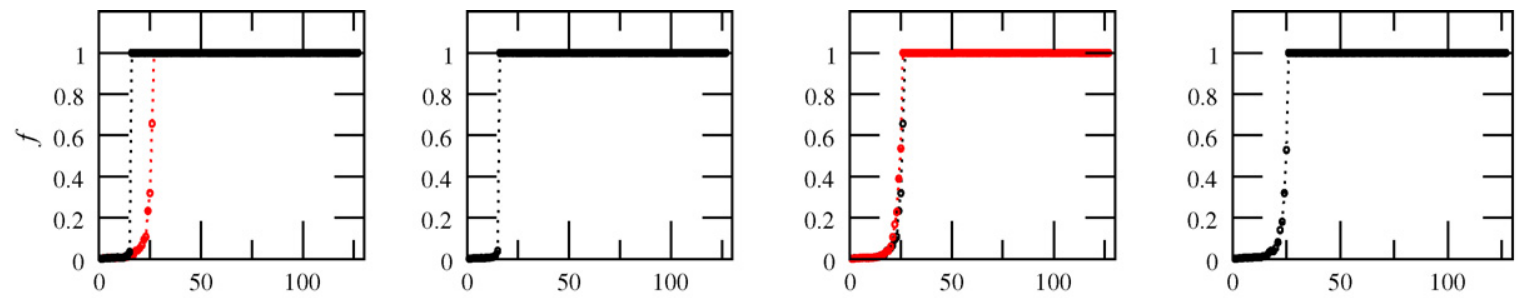

(a)
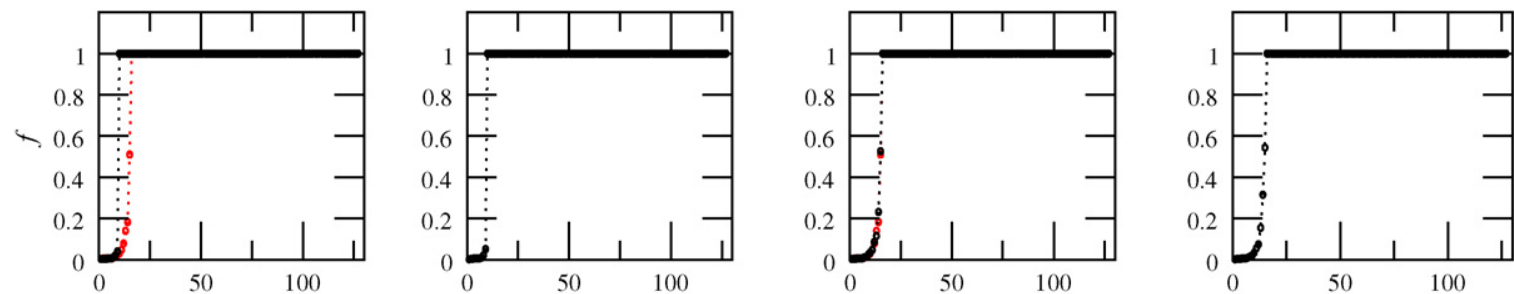

(b)
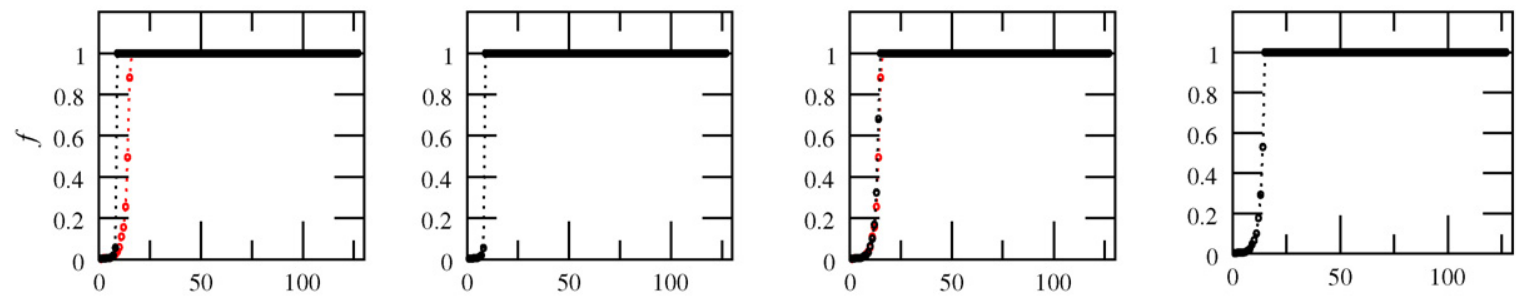

(c)
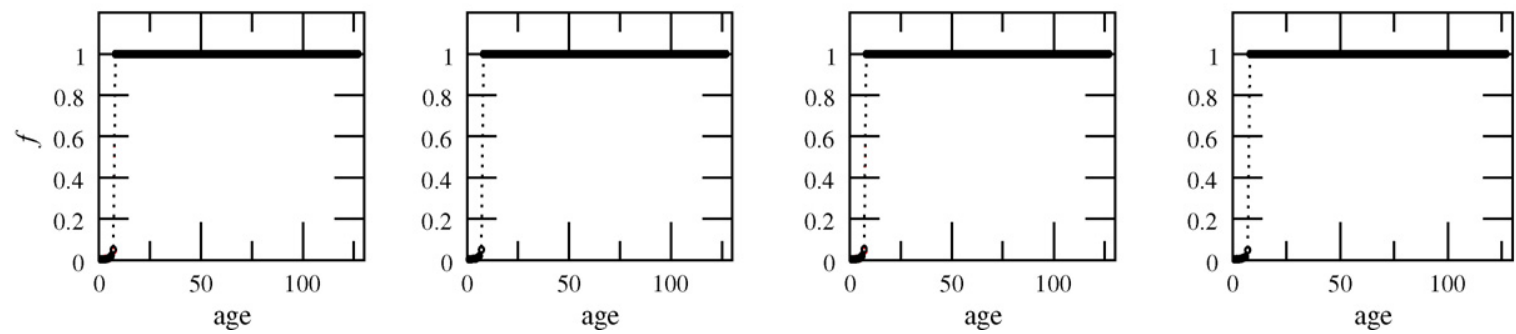

(d)

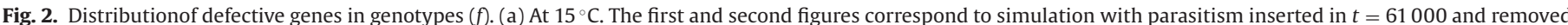

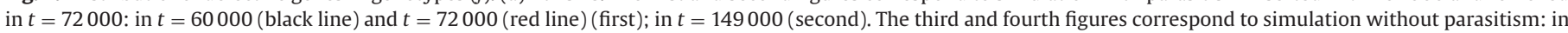

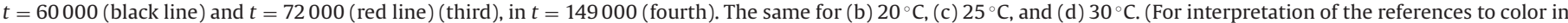
this figure legend, the reader is referred to the web version of the article.)

ity until the maximum age of reproduction $(R X)$. Alate morphs can disperse over great distances to colonize new plants. However, this generates an energy cost that generally is revealed by a fall in the fecundity or increase in the period of development (Pereira and Lomônaco, 2003). In such a way, the probability of reproduction of alate females is considered smaller than for apterous females. Moreover, alate females generate only apterous offspring (Mondor et al., 2005) with probability $\beta$, where $\beta$ is related to the energy cost. Apterous females will be able to generate alate offspring with probability $\epsilon$ and apterous offspring with probability $1.0-\epsilon$. Once the production of alate morphs is smaller in relation to apterous morphs (Pereira and Lomônaco, 2003), $\epsilon<1.0$. Parameters $\beta$ and $\epsilon$ assumed the following values:

- $\beta=0.30$

- $\epsilon=0.01$ and $\epsilon=0.12$.

Simulations were made up to 150000 time steps ("days"), considering an initial population of $N_{0}=10000$ females. The population dynamics basically follows the simple rules of the previous simulation.

\subsection{Results and discussion}

Figs. 4 and 5 show the survival curves and temporal evolution of the size of the population $(N(t))$, respectively, for colonies of aphids parasitized and non-parasitized at $25^{\circ} \mathrm{C}$ with $\epsilon=0.01$ and $\epsilon=0.12$. In this case, an increase in the production of alate morphs results to survival rates each time next to those gotten without parasitism (Fig. 4). After removal of the parasitoid, the average size of the population is restored if $\epsilon=0.12$. If $\epsilon=0.01$, the average size of the population is reduced by only $4.8 \%$ (in the absence of alates, the reduction was $7.8 \%$ (Fig. 5)).

Table 6 lists the average values for intrinsic growth rate $r_{m}(t)$ at $25^{\circ} \mathrm{C}$. It is observed that in the presence of parasitism, the reduction in average intrinsic growth rate decreases as $\epsilon$ increases. How-

Table 6

Average values for intrinsic growth rate (average \pm half-length of the $95 \%$ confidence interval) of $A$. gossypii at temperature of $25^{\circ} \mathrm{C}$.

\begin{tabular}{llll}
\hline$\epsilon$ & \multicolumn{4}{l}{ Average intrinsic growth rate } \\
\cline { 2 - 4 } & Absence of parasitism & During the parasitism & After parasitism \\
\hline 0.01 & $0.317 \pm 0.004$ & $0.054 \pm 0.012$ & $0.300 \pm 0.004$ \\
0.12 & $0.309 \pm 0.004$ & $0.080 \pm 0.008$ & $0.309 \pm 0.004$ \\
\hline
\end{tabular}



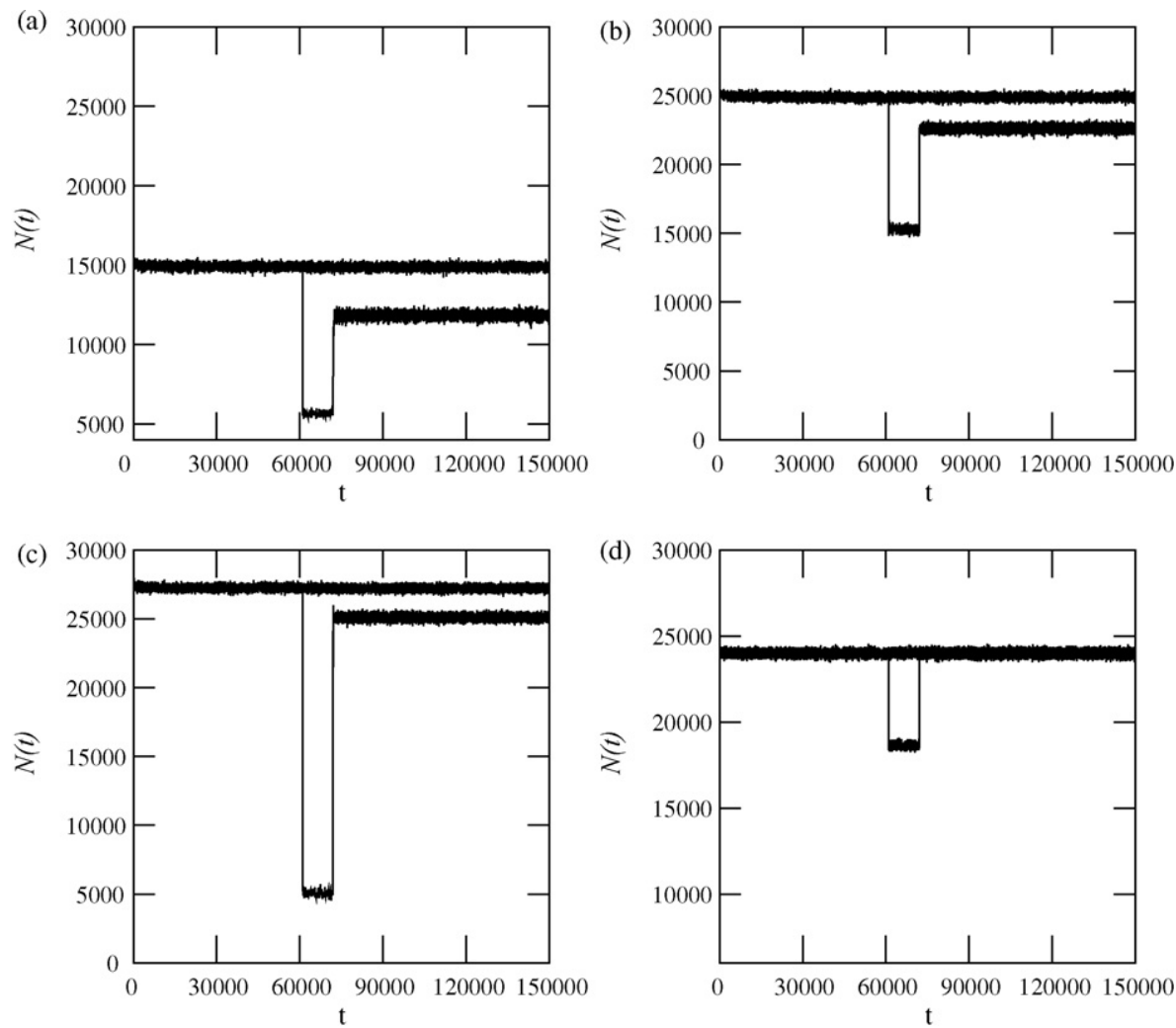

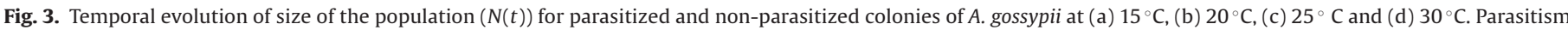
started in $t=61000$ and ended in $t=72000$. Simulations up to 150000 time steps.

ever, even for $\epsilon=0.01$, the difference between the average intrinsic growth rates in the absence and after the removal of parasitism is very small.

Fig. 6 shows the frequency of genotypes ( $f$ ) with defective genes at age $j$. It is observed that with the increase in the production of alate morphs, the distribution of genotypes after the removal of parasitism presents no significant differences in relation to distri-
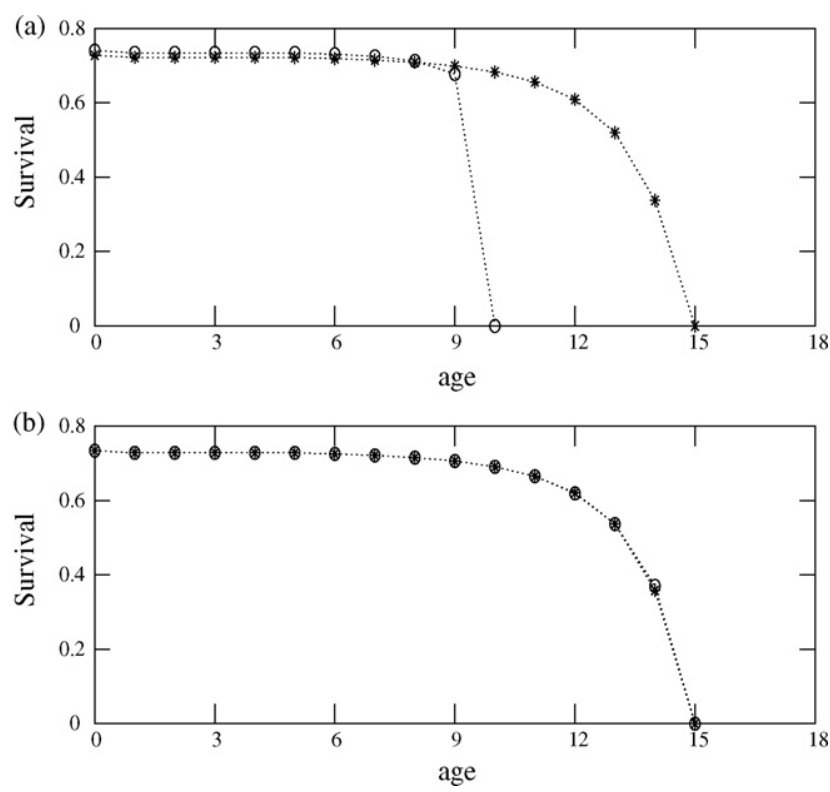

Fig. 4. Survival rates for parasitized (circle) and non-parasitized (star) colonies of A. gossypii. Parasitism on apterous morphs started in $t=61000$ and ended in $t=$ 72000 . Simulations up to 150000 time steps with (a) $\epsilon=0.01$ and (b) $\epsilon=0.12$. bution in the absence of parasitism. The presence of alate morphs in colonies of insects reduces selective pressure of parasitism and increases the probability of good genotypes to escape by flight of the action of the parasitoid and, in addition, allows these genotypes to remain in the population through successive generations.

Although results have been presented only with temperature at $25^{\circ} \mathrm{C}$, similar results were obtained for other temperatures ( 15 and $\left.20^{\circ} \mathrm{C}\right)$.
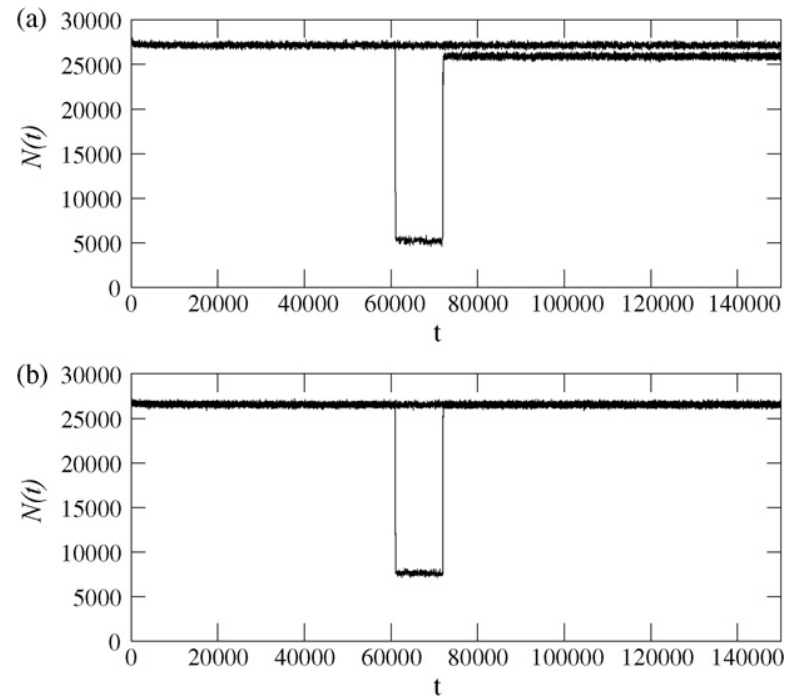

Fig. 5. Temporal evolution of size of the population $(N(t))$ for parasitized and non-parasitized colonies of $A$. gossypii. Parasitism on apterous morphs started in $t=61000$ and ended in $t=72000$. Simulations up to 150000 times steps with (a) $\epsilon=0.01$ and $(\mathrm{b}) \epsilon=0.12$. 
(a)

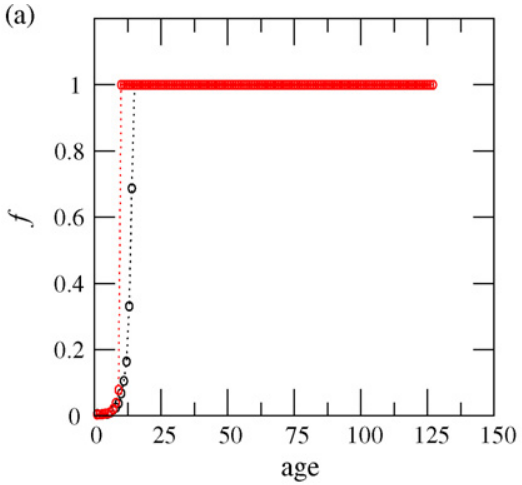

(c)

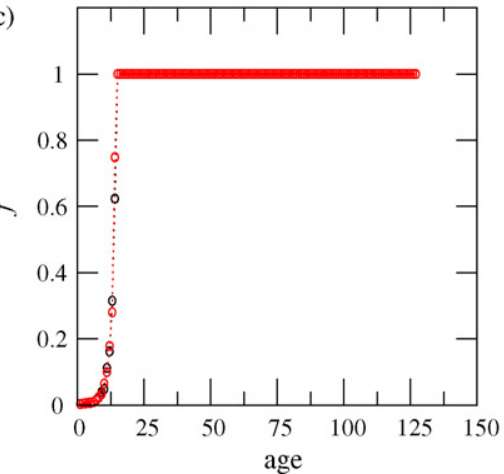

(b)

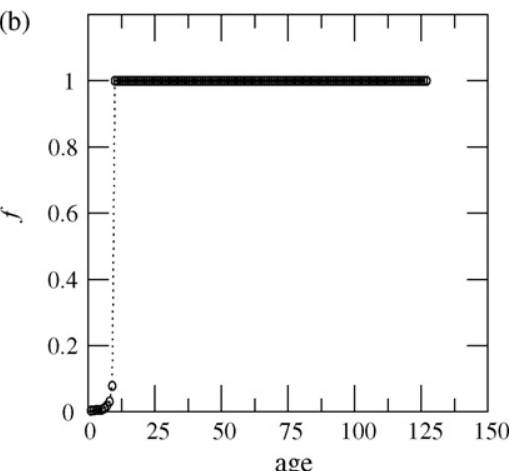

(d)

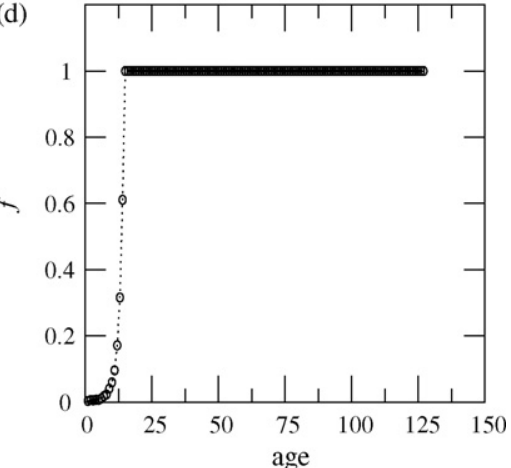

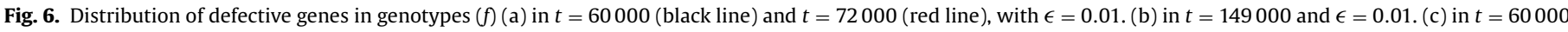

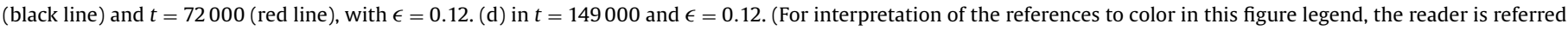
to the web version of the article.)

\section{Conclusions}

Although the proposed simulation is a simplification of the host-parasitoid interaction, it adequately represents the effects of this interaction on the population dynamics of the host, and, as such, can be a forecast model useful in biological control programs. As observed experimentally, the results show that the temperature of $25^{\circ} \mathrm{C}$ is the most adequate, among the temperatures tested, for the establishment of $L$. testaceipes as a biological control agent of $A$. gossypii in protected cultivation. Besides, playing another aspect observed in parasitized populations, the reduction in life expectancy as a result of selective pressure generated by parasitism.

According to the model, it is observed that the selective pressure generated by parasitism is able to change the distribution of genotypes of the population and therefore, affects the life expectancy and the growth rate of population. Furthermore, the results suggest that the emergence of alate morphs in the presence of parasitism should be a strategy for maintaining survival, as observed by Pereira and Lomônaco (2003). The presence of alate morphs reduces selective pressure of parasitism and increases the probability of good genotypes to remain in the population through successive generations.

In this work was treated the interaction between the aphid $A$. gossypii and its parasitoid L. testaceipes at different temperatures considering some biological data from both species. Other biological data, as well as the inclusion of the population of parasitoids can be incorporated into the model. Currently other work has been done in this direction. Moreover, other factors can be implemented, such as variations in temperature, precipitation and spatial distribution of species, which will allow treating other relevant issues in the host-parasitoid interaction.

Finally, the simulation model can provide support to the understanding of different aspects of host-parasitoid interaction and thus be a useful tool in establishing strategies in biological control.

\section{Acknowledgment}

We thank T.J.P. Penna for comments on this manuscript.

\section{References}

Bernardes, A.T., Moreira, J.G., Castro-e-Silva, A., 1998. Simulation of chaotic behaviour in population dynamics. Eur. Phys. J. B 1, 393-396.

Bommarco, R., Firle, S.O., Ekbom, B., 2007. Outbreak suppression by predators depends on spatial distribution of prey. Ecol. Mod. 201, 163-170.

Bueno, V.H.P., 2005. Controle Biológico de pulgões ou afídeos-praga em cultivos protegidos. Inf. Agrop. 26 (225), 9-17.

Duncan, A.B., Little, T.J., 2007. Parasite-driven genetic change in a natural population of Daphnia. Evolution 61 (4), 796-803.

Freire, R.M., Pregnolatto, S., Walder, J.M.M., Von Zuben, C.J., 2005. Modelagem matemática aplicada ao controle biológico de Ceratitis capitata Wiedemann (Diptera: Tephritidae) por Diachasmimorpha longicaudata Ashmed (Hymenoptera: Braconidae) em Citrus. Netrop. Entomol. 34 (2), 281-289.

Gardner, M.G., Schonrogge, K., Elmes, G.W., Thomas, J.A., 2007. Increased genetic diversity as a defence against parasites is undermined by social parasites: microdon mutabilis hoverflies infesting Formica lemani ant colonies. Proc. Biol. Sci. 274, 103-110.

Giarola, L.T.P., Martins, S.G.F., Toledo Costa, M.C.P., 2006. Computer simulation of Aphis gossypii insects using Penna aging model. Physica A 368 (1), 147-154.

He, X.Z., Wang, Q., Teulon, D.A.J., 2005. The effect of parasitism by Aphidius ervi on development and reproduction of the pea aphid. Acyrthosiphon pisum. New Zealand Plant Protection. 58, 202-207.

Mills, N.J., Getz, W.M., 1996. Modelling the biological control of insect pests: a review of host-parasitoid models. Ecol. Model. 92, 121-143.

Mondor, E.B., Rosenheim, J.A., Addicott, J.F., 2005. Predator-induced transgenerational phenotypic plasticity in the cotton aphid. Oecologia 142, 104-108.

Neto, S.S., Nakano, D.O., Barbin, N.A., 1976. Manual de ecologia dos insetos. Ed. Ceres, São Paulo, 419 pp.

Oliveira, A.C.S., Martins, S.G.F., Zacarias, M.S., 2008. Computer simulation of the coffee leaf miner using sexual Penna aging model. Physica A 387, 476-484.

Oliveira, S.M., Moss de, Penna, T.J.P., Stauffer, D., 1995. Simulating the vanishing of northen cod fish. Physica A 215, 298-304.

Penna, T.J.P., 1995. A bit string model for biological aging. J. Stat. Phys. 78 (5-6) 1629-1633.

Penna, T.J.P., de Oliveira, S.M., Moss de, Stauffer, D., 1995. Mutation accumulation and the catastrophic senescence of the Pacific salmon. Phys. Rev. E 52, R3309-R3312. 
Penna, T.J.P., Racco, A., Souza, A.O., 2001. Can microscopic models for age-structured populations contribute to ecology? Physica A 295, 31-37.

Pereira, C.D., Lomônaco, C., 2003. Produção de formas aladas em colônias de Brevicoryne brassicae (L.) (Hemiptera: Aphididae) por indução do parasitóide Diaeretiella rapae (McIntosh) (Hymenoptera: Aphidiidae) e alguns aspectos comportamentais da interação destas espécies. Neotrop. Entomol. 32 (1), 97-102.

Rodrigues, S.M.M., Bueno, V.H.P., Sampaio, M.V., Soglia, M.C.M., 2004. Influência da temperatura no desenvolvimento e parasitismo de Lysiphlebus testaceipes(Cresson)(Hymenoptera: Braconidae. Aphidiinae) em Aphis gossypii Glover (Hemiptera: Aphididae). Neotrop. Entomol. 33 (3), 341-346.

Sá Martins, J.S., Racco, A., 2001. Simulated emergence of cyclic sexual-asexual reproduction. Physica A 297, 485-494.

Sampaio, M.V., Bueno, V.H.P., Rodrigues, S.M.M., Soglia, M.C.M., 2005. Resposta à temperatura deAphidius colemani Viereck (Hymenoptera, Braconidae, Aphidiinae) originário de três regiões climáticas de Minas Gerais. Brasil. Rev. Bras. de Entomol. 49 (1), 141-147.
Soglia, M.C.M., Bueno, V.H.P., Sampaio, M.V., 2002. Desenvolvimento e sobrevivência de Aphis gossypii Glover (Hemiptera: Aphididae) em diferentes temperaturas e cultivares comerciais de crisântemo. Neotrop. Entomol. 31 (2), 211-216.

Soglia, M.C.M., Bueno, V.H.P., Rodrigues, S.M.M., 2003. Fecundidade e longevidade de Aphis gossypii Glover, 1877 (Hemiptera. Aphididae) em diferentes temperaturas e cultivares comerciais de crisântemo (Dendranthema grandiflora Tzvelev). Rev. Bras. de Entomol. 47 (1), 49-54.

Soglia, M.C.M., Bueno, V.H.P., Sampaio, M.V., 2005. Fertility life of Aphis gossypii on three commercial chrysanthemum cultivars. Integrated Control in Protected Crops. Temperate Climate IOBC/wprs Bulletin 28 (1), 241-244.

Stauffer, D., Proykova, A., Lampe, K.H., 2007. Monte Carlo simulation of agedependent host-parasite relations. Physica A 384, 387-391.

Weisser, W.W., Braendle, C., Minoretti, N., 1999. Predator-induced morphological shift in the pea aphid. Proc.: Biol. Sci. 266 (1424), 1175-1181.

Zambolim, L. (Ed.), 2000. Manejo Integrado, Doenças, Pragas e Plantas Daninhas. Departamento de Fitopalogia, UFV, Viçosa, p. 416. 